\title{
Managing acute abdominal pain in pediatric patients: current perspectives
}

This article was published in the following Dove Press journal:

Pediatric Health, Medicine and Therapeutics

29 June 2017

Number of times this article has been viewed

\section{Nadia M Hijaz \\ Craig A Friesen}

Division of Gastroenterology, Hepatology, and Nutrition, Children's Mercy Kansas City, Kansas City, MO, USA
Correspondence: Craig A Friesen Children's Mercy Kansas City, 240I Gillham Road, Kansas City, MO 64108, USA

$\mathrm{Tel}+\mathrm{I} 8162343712$

Fax + I 8168021465

Email cfriesen@cmh.edu
Abstract: Acute abdominal pain in pediatric patients has been a challenge for providers because of the nonspecific nature of symptoms and difficulty in the assessment and physical examination in children. Although most children with acute abdominal pain have self-limited benign conditions, pain may be a manifestation of an urgent surgical or medical condition where the biggest challenge is making a timely diagnosis so that appropriate treatment can be initiated without any diagnostic delays that increase morbidity. This is weighed against the need to decrease radiation exposure and avoid unnecessary operations. Across all age groups, there are numerous conditions that present with abdominal pain ranging from a very simple viral illness to a life-threatening surgical condition. It is proposed that the history, physical examination, laboratory tests, and imaging studies should initially be directed at differentiating surgical versus nonsurgical conditions both categorized as urgent versus nonurgent. The features of the history including patient's age, physical examination focused toward serious conditions, and appropriate tests are highlighted in the context of making these differentiations. Initial testing and management is also discussed with an emphasis on making use of surgeon and radiologist consultation and the need for adequate follow-up and reevaluation of the patient.

Keywords: acute abdominal pain, surgical abdomen, ultrasound

\section{Introduction}

Acute abdominal pain (AP) is a very common complaint for patients presenting to the emergency department (ED) and outpatient clinics. AP accounts for $\sim 5 \%-10 \%$ of visits to the ED. ${ }^{1}$ Acute AP is generally defined as pain of a nontraumatic origin with a maximum duration of 5 days. It can be caused by a variety of conditions ranging from mild and self-limiting to life-threatening diseases. An early and accurate diagnosis results in more appropriate management and, subsequently, leads to better outcomes and lower risk of morbidity. Causes for acute AP can be classified as urgent or nonurgent. Urgent causes require immediate treatment (within 24 hours or sooner if associated with ischemia) to prevent complications, whereas for nonurgent causes, immediate treatment is not necessary. ${ }^{2}$

Conditions that can be manifested by acute AP vary in incidence with age and sex. Classification of acute AP based on age is one adapted approach to narrow the differential diagnosis, which can guide selection of appropriate diagnostic tests, imaging, and definitive treatment. The five most prevalent nonsurgical diagnoses have been reported to be upper respiratory tract infection alone or complicated by otitis media 
or sinusitis (23.7\%), AP of uncertain etiology (15.4\%), gastroenteritis $(15.4 \%)$, constipation $(9.4 \%)$, and urinary tract infection $(8 \%){ }^{3}$

While most of the emergency visits presenting with acute abdominal pain are self-limited and benign medical diagnoses, a surgical etiology may be present in up to $20 \%{ }^{3}$ In nontraumatic cases of an acute abdomen below 1 year of age, the most common surgical etiology was reported to be incarcerated inguinal hernia (45.1\%), followed by intussusception $(41.9 \%)$. These etiologies were uncommon in school-age and adolescent children. In children above 1 year of age, the most common causes of acute surgical diagnoses have been reported to be acute appendicitis (64.0\%), incarcerated hernia (7.5\%), trauma (16.3\%), intussusception $(6.3 \%)$, intestinal obstruction $(1.3 \%)$, and ovarian torsion $(1.3 \%){ }^{4}$ Based on pathology reports of resected specimens, $15.6 \%$ of patients with appendicitis present with early appendicitis, $64.1 \%$ with suppurative or gangrenous changes, and $20.3 \%$ with perforated appendicitis. ${ }^{4}$

Despite the increased use of diagnostic laboratory and imaging modalities, acute AP remains a major diagnostic challenge. As already stated, the underlying causes for the acute AP vary across age groups. This leads to a large variation in choices regarding diagnostic modalities and treatment. The major challenges in children arise from often nonspecific symptoms, lack of classical presentation in many instances, and difficulty in performing a complete and reliable examination. In addition, avoidance of unnecessary radiation exposure associated with some diagnostic modalities, especially abdominal-pelvic computed tomography (CT) scan, and higher numbers of negative surgical explorations have become major concerns in children..$^{5-9}$

In a previous report, the diagnostic accuracy of acute AP increased when the focus of clinical evaluation was the differentiation between urgent and nonurgent conditions rather than a specific diagnosis. ${ }^{2}$ Sensitivity of medical history, physical examination, and laboratory values are higher for differentiating urgent from nonurgent conditions than for specific diagnoses. ${ }^{2}$ Therefore, it is highly reasonable to adapt an evidence-based simple approach in decision making to be used by practitioners when evaluating children with acute AP directed toward an age-specific focus on eliminating urgent diagnoses in which any delay may impact the outcome significantly. We propose a modified differential diagnosis and approach based not only on age but also on differentiating medical versus surgical etiologies both categorized by the urgency in which management must be initiated (see Table 1).

\section{Evaluation}

The evaluation of acute AP includes a thorough history and physical examination and often will also involve laboratory tests and/or imaging studies. In patients who appear ill, as discussed subsequently, the initial evaluation step is consultation with a surgeon who should direct the initial diagnostic steps to make a decision regarding whether the patient should be taken to the operating room. Likewise, the evaluating provider should make liberal use of consultation with a radiologist when contemplating the best imaging studies for a particular patient concern as the radiologist not only has expertise in this area but also knowledge of the local experience and capabilities.

\section{History and physical examination}

Guidelines for diagnostic evaluation of acute AP in adults propose that the diagnostic accuracy of clinical assessment is insufficient to identify the correct diagnosis but can discriminate between urgent and nonurgent causes and justify the choice for additional imaging in suspected urgent conditions. ${ }^{10}$ Patients suspected of nonurgent diagnoses can be safely reevaluated at later times without increased risk of morbidity. The most practical approach is to make the distinction between medical and surgical causes by initially relying on a thorough history and physical examination focused on differentiating factors as generally described in Table 2. Obtaining a detailed history, assessing vital signs, and making an initial assessment of the patient's overall appearance can help triage between critically ill patients where an urgent surgical procedure is needed and those who are clinically stable.

The history is directed toward three components: the pain itself, associated symptoms, and predisposing conditions. Key points regarding AP should include pain location, radiation, intensity and nature of pain, previous episodes of AP, and the intensity or progression of the pain, as well as associated symptoms. Patients with midline pain, those without any increase in pain and without vomiting, and those with weak or moderate pain tend to have more nonspecific benign AP. ${ }^{11,12}$ In the acute surgical abdomen, pain generally precedes vomiting, while the reverse is true with medical causes. ${ }^{13}$ Acute-onset severe and colicky, localized AP suggests an intra-abdominal surgical etiology such as intussusception. ${ }^{14}$ However, only one third of patients with intussusception present with the classical presentation (bloody mucousy stool, colicky AP, and rectal or abdominal mass), so the provider must consider the diagnosis based on age in the absence of classical findings. ${ }^{15}$ An intra-abdominal inflammatory process is suggested when a child has fever 
Table I Classification of acute abdominal pain based on age and severity

\begin{tabular}{|c|c|c|c|}
\hline $\begin{array}{l}\text { Surgical condition that } \\
\text { requires immediate care }\end{array}$ & $\begin{array}{l}\text { Medical condition that } \\
\text { warrants immediate } \\
\text { management }\end{array}$ & $\begin{array}{l}\text { Surgical nonemergent } \\
\text { condition but requires } \\
\text { invasive management }\end{array}$ & $\begin{array}{l}\text { Medical condition that does } \\
\text { not warrant immediate } \\
\text { management }\end{array}$ \\
\hline \multicolumn{4}{|l|}{ 0-6 months of age } \\
\hline Incarcerated inguinal hernia & Sepsis/bacteremia & Hypertrophic pyloric stenosis* & Gastroesophageal reflux disease \\
\hline Malrotation and volvulus & Gastroenteritis with dehydration & Hirschsprung's disease* & Infantile colic \\
\hline Intestinal obstruction & UTI & Hydroceles & Constipation \\
\hline Intussusception & & & Milk protein allergy \\
\hline \multicolumn{4}{|l|}{6 months to 5 years } \\
\hline Appendicitis & DKA & Meckel's diverticulum* & Food allergies \\
\hline Malrotation and volvulus & Sickle cell crisis & Hirschsprung's disease* & Lactose intolerance \\
\hline \multirow[t]{7}{*}{ Intussusception } & $\begin{array}{l}\text { Ureteric calculi and acute renal } \\
\text { disease }\end{array}$ & & Constipation \\
\hline & Acute pancreatitis & & Viral infective gastroenteritis/colitis \\
\hline & Complicated PUD & & \\
\hline & Bacterial infections, including: & & \\
\hline & - Pneumonia/otitis media & & \\
\hline & - Strep throat/tonsillitis & & \\
\hline & $\begin{array}{l}\text { - Infective gastroenteritis/colitis/ } \\
\text { hepatitis } \\
\text { - UTI }\end{array}$ & & \\
\hline \multicolumn{4}{|l|}{$5-18$ years } \\
\hline Appendicitis & DKA & Gallstones & Viral gastroenteritis/viral syndrome \\
\hline Complicated acute cholecystitis & Sickle cell crisis & Foreign body* & Constipation \\
\hline Testicular torsion & & $\begin{array}{l}\text { Noncomplicated hepatobiliary } \\
\text { disease and noncomplicated acute } \\
\text { cholecystitis* }\end{array}$ & Mononucleosis \\
\hline Ectopic pregnancy, ovarian torsion & Acute complicated pancreatitis & & HSP \\
\hline $\begin{array}{l}\text { Small bowel obstructions and } \\
\text { adhesions }\end{array}$ & Complicated PUD & & Mesenteric adenitis \\
\hline Obstructed inguinal hernia & Hemolytic-uremic syndrome & & Gastroduodenitis, PUD \\
\hline Intestinal volvulus & Renal vein thrombosis & & Food poisoning \\
\hline $\begin{array}{l}\text { Complicated inflammatory bowel } \\
\text { disease }\end{array}$ & $\begin{array}{l}\text { Bacterial infections, including: } \\
\text { - Pneumonia/otitis media } \\
\text { - Strep throat/tonsillitis } \\
\text { - Infective gastroenteritis/colitis/ } \\
\text { hepatitis } \\
\text { - UTI }\end{array}$ & & $\begin{array}{l}\text { Tubo-ovarian disease, ovarian cyst/ } \\
\text { menstrual pain, pelvic inflammatory } \\
\text { disease, sexually transmitted disease }\end{array}$ \\
\hline
\end{tabular}

Note: *Condition considered nonemergent unless it is complicated with perforation, bleeding, or peritonitis.

Abbreviations: DKA, diabetic ketoacidosis; HSP, Henoch-Schönlein purpura; PUD, peptic ulcer disease; UTI, urinary tract infection.

and abdominal tenderness in conjunction with bilious vomiting (bowel obstruction) and bloody stool (bowel ischemia). Having progressive pain preceding vomiting, nausea, lack of appetite, diarrhea, and fever with AP suggest acute appendicitis in children. ${ }^{13}$ Quality and radiation of pain is not a strong predictor of acute appendicitis, and the classical presentation is usually lacking. ${ }^{13}$ Similarly, evidence indicates that a weak or absent inflammatory response, female sex, long duration of symptoms, and absence of vomiting (rather than relying on pain quality or severity of tenderness) are predictors of negative surgical explorations in patients with suspected appendicitis. ${ }^{16}$
It is important to obtain information about other associated symptoms because of the variety of nongastrointestinal etiologies causing AP in children. Acute AP if associated with normal appetite, short duration of pain, renal (flank) tenderness, and/or hematuria (erythrocytes $>10$ ) is indicative of acute renal colic. ${ }^{17,18} \mathrm{AP}$ with cough, shortness of breath, or sore throat can be due to respiratory infection. Urinary symptoms can indicate a urinary tract infection or pyelonephritis. In pubertal girls, it is important to ask about menstrual history and sexual activity. Vaginal discharge, with or without fever, irregular spotting, or abnormal menstrual bleeding with pain can indicate pelvic inflammatory disease (PID). 
Table 2 Differentiating surgical from nonsurgical conditions and suggested initial testing

\begin{tabular}{|c|c|c|}
\hline Evaluation & Surgical & Nonsurgical \\
\hline \multirow[t]{6}{*}{ History } & Acute, severe pain, more localized & Midline or generalized pain \\
\hline & Pain increasing in intensity & Stable pain intensity \\
\hline & Pain precedes vomiting & Vomiting absent or precedes pain onset \\
\hline & Bilious vomiting & Long duration of pain \\
\hline & Hematochezia & \\
\hline & Previous abdominal surgery & \\
\hline \multirow[t]{6}{*}{ Physical examination } & III appearing & Nondistended normal bowel sounds \\
\hline & Lethargic & Diffuse tenderness \\
\hline & Abdominal distension & No rigidity or rebound tenderness \\
\hline & Absent or high-pitched bowel sounds & \\
\hline & Localized tenderness & \\
\hline & Peritoneal signs (rebound tenderness, rigidity, guarding) & \\
\hline \multirow[t]{4}{*}{ Initial evaluation } & Labs: complete blood count, electrolytes, liver function tests, & Depends on signs and symptoms \\
\hline & amylase, lipase, and urinalysis; pregnancy test in females & \\
\hline & Imaging: acute abdominal series (if previous abdominal surgery, & \\
\hline & distension, or bilious vomiting); abdominal ultrasound & \\
\hline
\end{tabular}

Past medical history is important to identify specific causes of acute AP and partially to exclude the possibility that the current attack of pain is actually an ongoing manifestation of chronic AP. However, the evaluating provider needs to assess for an urgent condition even in a patient with chronic $\mathrm{AP}$ as chronic pain is not protective against acute conditions such as appendicitis. All previous hospitalizations or significant illnesses such as sickle cell anemia and porphyria should be noted. A history of previous surgery not only can eliminate certain diagnoses but also can increase the risk of others, such as intestinal obstruction from adhesions. A detailed drug history is vital to exclude possible ingestions in children.

The physical examination of a child with acute AP should begin with an overall assessment of the child's appearance (lethargy, eye contact, comforted by family member, and interactive), hydration status, activity level, and vital signs. Patients with peritonitis tend to lie very still, whereas those with renal colic seem unable to stay still. Fever suggests infection; however, its absence does not rule it out, especially in patients who are immunocompromised. Fever indicates an underlying infection or inflammation. High fever with chills is typical of pyelonephritis and pneumonia. ${ }^{19,20}$ Tachycardia and hypotension suggest hypovolemia. If a postmenarcheal girl is in shock, ectopic pregnancy or toxic shock syndrome should be suspected. Hypertension may be associated with renal disease, and Henoch-Schönlein purpura (HSP) or hemolytic-uremic syndrome should be highly considered..$^{21,22}$ Deep, labored respiration may indicate diabetic ketoacidosis. Abdominal examination should be performed gently with careful hands-off inspection being the first step. Distracting the child while palpating the abdomen is very helpful. A young child is best examined in a parent's arms or lap.
For a patient who appears critically ill, the initial concern is to immediately rule out surgical diagnoses particularly those associated with obstruction or ischemia as in Table 1. A more urgent surgical diagnosis is likely if there is distension, peritoneal signs, and abnormal bowel sounds. ${ }^{12,13} \mathrm{~A}$ provider must keep in mind that abdominal distension may be absent in patients with gastric outlet or proximal small bowel obstructions which can be seen, for example, in cases of proximal intussusceptions in patients with HSP. ${ }^{23}$ This is particularly true in patients who have recently vomited as they may decompress the gastrointestinal tract proximal to the obstruction such that abdominal distension may be absent and some imaging studies (eg, abdominal radiograph or ultrasound [US]) may be normal.

Peritoneal signs including localized tenderness, rebound tenderness, and involuntary or voluntary guarding are indicative of an acute surgical abdomen. Tachycardia (pulse $>100$ beats/min), guarding, and rebound tenderness are significantly more common in children with acute appendicitis. ${ }^{13}$ Moreover, pain $<48$ hours in duration followed by vomiting, guarding, and rebound tenderness on physical examination, particularly if there is a history of a prior surgical procedure, indicates a patient with high risk of an acute surgical abdomen. ${ }^{14}$ The presence of these features demands careful evaluation, surgical consultation, and admission and observation. ${ }^{14}$ It is suggested that positive palpatory findings like rigidity and guarding are helpful diagnostic indicators for surgical conditions, whereas negative palpatory findings have little value in excluding surgical conditions entirely. ${ }^{24}$

Examination of all body systems is mandated, including throat, ears, skin, and genitals. By doing so, additional surgical conditions that need immediate attention can be 
uncovered including incarcerated hernia and testicular torsions where delay in diagnosis can have a significant morbidity. In addition, the physical examination can diagnose medically treatable conditions such as ear and throat infections. Rectal examination may be necessary to identify a perianal lesion or occult blood in the stool and possibly helpful for fecal disimpaction. However, routine rectal examination is of little value for diagnosing appendicitis, peritonitis, or small bowel obstruction. ${ }^{24}$ Pelvic examination is required in pubertal girls to evaluate for pregnancy complications and sexually transmitted infections. Scrotal examination is mandatory in boys with acute AP to evaluate for testicular torsion even in the absence of testicular pain. ${ }^{25}$ Swelling and erythema of the scrotal sac or horizontal position of the testicle are indicative of possible torsion. ${ }^{25}$ Absence of the testicle in the scrotum should raise suspicion of a possible torsion of an undescended testicle. ${ }^{26}$

\section{Diagnostic laboratory tests}

Although appropriate diagnostic laboratory testing varies based on the clinical situation, a complete blood count (CBC), erythrocyte sedimentation rate (ESR), C-reactive protein (CRP), and urinalysis can be considered as initial laboratory tests as suggested by American Family Physician recommendations for evaluating patients with acute AP. ${ }^{27}$ However, it is important to be aware that there are no laboratory tests that sufficiently differentiate between surgical and nonsurgical conditions, and more definitive testing should not be delayed while awaiting laboratory test results. Although a $\mathrm{CBC}$ is appropriate if a serious infection or blood loss is suspected, $\mathrm{CBC}$, ESR, or CRP alone do not appear to differentiate between urgent and nonurgent diseases. ${ }^{28}$ Neither a CBC nor a CRP can safely and adequately rule-in or rule-out the diagnosis of acute appendicitis in patients who present with AP of 5 days or less in duration. ${ }^{14,29}$ Leukocytosis alone is not predictive of a surgical disease as the white blood cell (WBC) count lacks sufficient sensitivity or specificity to be a good predictor of an acute surgical abdomen. ${ }^{30,31}$ Clinical predictive tools for diagnosis of acute appendicitis such as the Pediatric Appendicitis Score and Alvarado use leukocytosis and elevated polymorphonuclear cells $>75 \%$ as parameters in order to reduce uncertainty and improve diagnostic accuracy, however, neither met the current performance requirements. ${ }^{32}$ When a clinically nonurgent condition is suspected but the CRP is above $100 \mathrm{mg} / \mathrm{L}$ or the WBC count is above $15 \times 10^{9} / \mathrm{L}$, the possibility of an urgent surgical condition should be reconsidered and additional imaging may be warranted..$^{2,28,33,34}$ While, in general, laboratory tests do not sufficiently differentiate between surgical and nonsurgical cases, they may be helpful in identifying associated morbidity. For example, in the setting of a possible bowel obstruction, electrolytes should be obtained as acidosis may indicate impending decompensation or sepsis. Also, laboratory tests may be helpful in identifying urgent medical conditions that may mimic surgical diseases such as severe pancreatitis or pyelonephritis. The suggested initial work-up including laboratory tests in patients who appear to have an acute surgical condition is shown in Table 2.

The need for other laboratory tests can be determined based on the suspicion of a specific diagnosis. See Table 3 for suggested initial evaluations. A positive diagnosis of pancreatitis requires two of three of the following: compatible symptoms (eg, AP and/or vomiting), amylase and/or lipase $\geq 3 \times$ the upper limit of normal, and radiographic (US or CT) evidence of pancreatitis. ${ }^{35}$ For patients with epigastric pain with or without radiation to the back, simultaneous amylase and lipase measurements are recommended but it should be noted that an elevated lipase level with a normal amylase level is not likely to be caused by pancreatitis. ${ }^{36,37} \mathrm{~A}$ urinalysis should be obtained in all patients with hematuria, gross dysuria, or flank pain. ${ }^{20} \mathrm{~A}$ urinary tract infection is more likely in a febrile female patient if there is absence of another source

Table 3 Suggested initial evaluation in patients suspected of having nonurgent condition associated with abdominal pain

\begin{tabular}{|c|c|}
\hline Symptoms & Evaluation \\
\hline $\begin{array}{l}\text { Upper or epigastric abdominal } \\
\text { pain (particularly with vomiting) }\end{array}$ & $\begin{array}{l}\text { Liver function tests, amylase, and } \\
\text { lipase; ultrasound }\end{array}$ \\
\hline Periumbilical or diffuse pain & $\begin{array}{l}\text { CBC, electrolytes, glucose, UA, and } \\
\text { consider throat culture }\end{array}$ \\
\hline Localized RLQ pain & $\begin{array}{l}\text { CBC, ESR, CRP, and stool } \\
\text { calprotectin; ultrasound, Yersinia } \\
\text { culture }\end{array}$ \\
\hline Lower abdominal pain & UA; ultrasound \\
\hline $\begin{array}{l}\text { Genital or scrotal pain/vaginal } \\
\text { discharge }\end{array}$ & Ultrasound \\
\hline Hematemesis & $\begin{array}{l}\text { CBC, amylase, lipase, and liver } \\
\text { function tests; ultrasound }\end{array}$ \\
\hline Hematochezia & $\begin{array}{l}\text { CBC, ESR, CRP, stool calprotectin, } \\
\text { BUN, creatinine; stool culture and } \\
\text { Clostridium difficile testing if fever } \\
\text { present; ultrasound }\end{array}$ \\
\hline $\begin{array}{l}\text { Hematuria, flank pain, or } \\
\text { suprapubic pain }\end{array}$ & $\begin{array}{l}\text { UA and urine culture; ultrasound } \\
\text { and/or CT }\end{array}$ \\
\hline Polyuria & Electrolytes, glucose, and UA \\
\hline $\begin{array}{l}\text { Weight loss or growth } \\
\text { deceleration }\end{array}$ & $\begin{array}{l}\text { CBC, ESR, CRP, and stool } \\
\text { calprotectin, and celiac serology }\end{array}$ \\
\hline $\begin{array}{l}\text { Diarrhea without fever or } \\
\text { hematochezia }\end{array}$ & Stool ova and parasite \\
\hline
\end{tabular}

Abbreviations: AAS, acute abdominal series; BUN, blood urea nitrogen; $C B C$, complete blood count; CRP, C-reactive protein; CT, computed tomography; ESR, erythrocyte sedimentation rate; RLQ, right lower quadrant; RUQ, right upper quadrant; UA, urinalysis; US, ultrasound of abdomen. 
of fever on examination, foul-smelling urine, or a WBC count $>15,000 / \mathrm{mm}^{3}$ in a patient younger than 6 months old. ${ }^{38,39} \mathrm{~A}$ urine pregnancy test should be routinely performed in all adolescent females who have AP to narrow the differential diagnosis and to determine whether certain imaging studies are appropriate. Although right lower quadrant (RLQ) pain alone in adolescent females is not specific for appendicitis or PID, the presence of anorexia and the onset of pain later than day 14 of the menstrual cycle favor appendicitis, while a history of vaginal discharge, urinary symptoms, prior PID, tenderness outside the RLQ, cervical motion tenderness, vaginal discharge on pelvic examination, and/or positive urinalysis favor PID. ${ }^{40}$

A blood glucose check is recommended if AP is associated with polyuria or polydipsia or with changes in metal status, to rule out diabetic ketoacidosis, an urgent medical condition. The American Academy of Pediatrics recommends electrolytes in children who have acute gastroenteritis with, among other signs, an altered mental status, clinical signs of moderate-to-severe dehydration, clinical signs of hypernatremia or hypokalemia, prolonged severe diarrhea, or suspicious unusual histories. ${ }^{41}$ In cases of right upper quadrant pain, jaundice, signs of chronic liver disease (eg, spider angiomas), or changes in mental status, a prompt chemistry panel, albumin, and liver function tests should be obtained. Obtaining lab tests for clinical suspicion of acute cholecystitis is not indicated because there are no clinical finding or laboratory tests sufficient to establish or exclude cholecystitis without further imaging. ${ }^{42}$

Children presenting with acute gastroenteritis do not require routine etiological investigation; however, microbiological studies should be considered in cases such as severe acute gastroenteritis requiring admission, systemic illness, travel history, daycare exposure, a food- or water-borne source, recent antibiotics, bloody or mucoid stools, immunocompromised patients, or in areas experiencing epidemics. ${ }^{41}$

In summary, laboratory tests can narrow a differential diagnosis, confirm clinical suspicion of a disease process, or exclude it, but can also be confounding factors and are not adequate to differentiate surgical from nonsurgical conditions. Therefore, it suggested that lab testing generally be obtained to answer a focused clinical question. ${ }^{10}$

\section{Imaging}

Several studies have demonstrated that the accuracy of clinical evaluation is often insufficient for determining the correct specific diagnosis. ${ }^{2,28,33,34}$ Additional imaging modalities can increase diagnostic certainty. Abdominal radiographs are not routinely necessary or helpful in evaluating acute AP unless the patient has had previous abdominal surgery, demonstrates abnormal bowel sounds or abdominal distension, has a history of ingesting a radiopaque foreign body, or demonstrates peritoneal signs. ${ }^{43,44}$ Radiography may identify pneumonia in right or left upper quadrant pain, a renal or ureteric calculus, abdominal mass, and bowel perforation with free air. ${ }^{45-47}$ Although abdominal radiographs are routinely obtained in the ED to evaluate for constipation, this practice is discouraged. Clinical guidelines for pediatric constipation recommend against the use of abdominal radiographs to make the diagnosis of functional constipation as there is inconsistency in interpretation and they lack adequate sensitivity or specificity. ${ }^{48}$ Additionally, obtaining abdominal radiographs has been found to be associated with more frequent misdiagnoses. ${ }^{49}$

When there is concern for a surgical condition, abdominal US is the preferred initial imaging in pediatric patients. ${ }^{6-9,46,50}$ US has a sensitivity of $90 \%-96 \%$, specificity of $94 \%-98 \%$, and accuracy of $94 \%$ in the diagnosis of acute appendicitis in pediatric patients. ${ }^{51,52}$ The sensitivity of ultrasonography is decreased in centers where it is used less often, when the appendix is not clearly visualized, and when there is shorter duration of pain. ${ }^{53,54}$ It is a reliable imaging modality not only for the diagnosis of surgical cases but also for many nonsurgical conditions. There is a trend toward increased use of bedside US examination as it is linked to higher satisfaction and decreased short-term health-care consumption. ${ }^{55}$ Ultrasonography can be used to evaluate for bowel thickening, focal intramural bowel hematomas in HSP, and bowel "target" or "donut" signs in intussusception. ${ }^{15,22}$ It is also the preferred imaging choice for cholecystitis, pancreatitis, hydronephrosis, ovarian cysts, ovarian torsion, and pregnancy complications..$^{6-9,46,47}$ However, many factors can affect the accuracy of ultrasonography, including obesity, free air, scar tissue, or US technician inexperience. Providers in EDs, therefore, may need additional diagnostic tools after consulting with a radiologist when doubt exists about the need for surgical intervention.

Because of radiation exposure, guidelines suggested by American College of Radiology and the American College of Emergency Physicians discourage the use of CT in the routine evaluation of suspected appendicitis in children until ultrasonography has been considered as an option. ${ }^{9,56}$ Although $\mathrm{CT}$ is the most sensitive imaging investigation for detecting urgent conditions in patients with AP, using ultrasonography first and CT only in those with negative or inconclusive ultrasonography results in the best sensitivity and lowers exposure to radiation in children..$^{2,9,47}$ Only in critically ill patients 
should a CT be performed without a prior US. ${ }^{2,10}$ CT is suggested to evaluate for complications such as necrosis from pancreatitis or complicated appendicitis, to diagnose omental torsion, to identify an etiology for a bowel obstruction, or in patients with marked obesity. ${ }^{46,48,57}$ The introduction of multidetector row CT has further enhanced the utility of CT in imaging patients with acute AP. ${ }^{57}$ In patients with RLQ pain, the positive diagnostic yield of abdominal CT in pediatric patients is increased in males and those with elevated WBC count, neutrophil-to-lymphocyte ratio $>5$, and CRP $>1 \mathrm{mg} /$ $\mathrm{dL}$ while only leukocytosis increased the yield in those with non-RLQ pain. ${ }^{58}$

Magnetic resonance imaging would be ideal imaging for the diagnosis of surgical AP with no radiation exposure in children or pregnant teens and because it has high sensitivity and specificity for many intra-abdominal diseases. The advantage of MRI over CT is that no administration of contrast media is necessary and that there is no ionizing radiation exposure. However, it is considered an expensive and time-consuming test. Also, it is not readily available in many EDs and it may require sedation in children. For pregnant women, when there is suspicion of an urgent condition, an MRI should be considered because of the serious consequences of a missed diagnosis. ${ }^{53,54}$

\section{Management of acute AP}

Treatment should be directed at the underlying cause when it can be identified. While the treatment of each specific condition is beyond the scope of the current manuscript, some general points deserve discussion. In patients with a high suspicion of a surgical condition, urgent consultation with a specific specialty such as surgery, gynecology, or urology is mandated while the patient is getting stabilized with adequate hydration and pain control. After surgical and urgent medical conditions have been excluded, discharge from the ED or acute care clinic with education regarding worrisome signs and symptoms and very close follow-up is generally a safe approach with children. ${ }^{10}$ Children who are discharged should be in stable condition with normal vital signs and oxygen saturations and with adequate pain relief. Children who do not meet these criteria or appear more than mildly ill should be admitted to the hospital to allow continuous monitoring and frequent reevaluation. Reevaluation as an inpatient or outpatient needs to continue until pain resolves. Worsening pain or development of new symptoms should prompt reevaluation.

Pediatric patients in general are at risk for receiving less than optimal analgesia. ${ }^{59}$ In the setting of acute AP, providers are often concerned about the possibility that strong analgesia (eg, opioids) may mask symptoms and result in complications and increased morbidity. Several prospective, randomized studies have shown that judicious use of analgesia may enhance diagnostic accuracy by permitting a more thorough physical examination. ${ }^{60}$ It appears that opioids may be used to treat acute AP in children without delaying the diagnosis. ${ }^{60}$ A systematic review and meta-analysis of opioid use in children with acute appendicitis demonstrated that opioids were not associated with an increased risk of perforation or abscess. ${ }^{59}$ However, the analysis also revealed that children were often treated with doses that did not provide adequate analgesia. ${ }^{59}$ As a general rule, adequate pain control should be a therapeutic goal and this appears safe especially if there is frequent reevaluation of the patient's condition.

In patients identified as having nonurgent medical conditions, initial empiric therapy based on symptoms may be initiated in the absence of an established diagnosis. For patients with upper AP, acid suppression represents a reasonable initial approach that would be consistent with the usual treatment pathway for patients with chronic upper AP or dyspepsia. ${ }^{61}$ For patients with a history of constipation such as less frequent stools, hard or painful stools, or those with palpable stool in the left lower quadrant, treatment with a stool softener or osmotic laxative may be initiated or the patient may be given an enema in the acute care setting to see if pain improves with a stool. Finally, in the absence of constipation, lower AP or crampy, more diffuse pain may be treated with an antispasmodic medication. Close followup and reevaluation of response are required in all patients treated symptomatically.

\section{Conclusion}

The most important and most attainable initial goal in the evaluation of acute AP is to differentiate surgical and nonsurgical conditions with each further categorized as urgent versus nonurgent. This can often be achieved by a thorough history and physical examination, laboratory testing to primarily assess comorbidity, and imaging studies. In an ill-appearing patient, work-up and management decisions should involve collaboration between the acute setting provider, a surgeon, and a radiologist. Once an urgent condition is excluded, serial reevaluation and symptomatic treatment with close follow-up are the mainstays of management.

\section{Disclosure}

The authors report no conflicts of interest in this work. 


\section{References}

1. Caperell K, Pitetti R, Cross KP. Race and acute abdominal pain in a pediatric emergency department. Pediatrics. 2013;131(6):1098-1106.

2. Laméris W, van Randen A, van Es HW, et al. Imaging strategies for detection of urgent conditions in patients with acute abdominal pain: diagnostic accuracy study. BMJ. 2009;338:b2431.

3. Erkan T, Cam H, Ozkan HC, et al. Clinical spectrum of acute abdominal pain in Turkish pediatric patients: a prospective study. Pediatr Int. 2004;46(3):325-329.

4. Tseng YC, Lee MS, Chang YJ, Wu HP. Acute abdomen in pediatric patients admitted to the pediatric emergency department. Pediatr Neonatol. 2008;49(4):126-134.

5. Miglioretti DL, Johnson E, Williams A, et al. The use of computed tomography in pediatrics and the associated radiation exposure and estimated cancer risk. JAMA Pediatr. 2013;167(8):700-707.

6. Yarmish GM, Smith MP, Rosen MP, et al. American College of Radiology. ACR appropriateness criteria. Right upper quadrant pain. Available from: http://www.guideline.gov/summaries/summary/47653. Accessed January 23, 2016.

7. Bhosale PR, Javitt MC, Atri M, et al. ACR appropriateness criteria. Acute pelvic pain in the reproductive age group. Ultrasound $Q$. 2016;32(2): $108-115$.

8. Karmazyn B, Coley BD, Binkovitz LA, et al. American College of Radiology. ACR appropriateness criteria. Urinary tract infection-child. Available from: http://www.guideline.gov/summaries/summary/50499. Accessed January 23, 2016.

9. Smith MP, Katz DS, Rosen MP, et al. American College of Radiology. ACR appropriateness criteria. Right lower quadrant pain - suspected appendicitis. Ultrasound Q. 2015;31(2):85-91.

10. Gans SL, Pols MA, Stoker J, Boermeester MA; expert steering group. Guideline for the diagnostic pathway in patients with acute abdominal pain. Dig Surg. 2015;32(1):23-31.

11. Eskelinen M, Lipponen P. Usefulness of history-taking in non-specific abdominal pain: a prospective study of 1333 patients with acute abdominal pain in Finland. In Vivo. 2012;26(2):335-339.

12. Eskelinen M, Ikonen J, Lipponen P. Contributions of history-taking, physical examination, and computer assistance to diagnosis of acute small-bowel obstruction. A prospective study of 1333 patients with acute abdominal pain. Scand J Gastroenterol. 1994;29(8):715-721.

13. Williams NM, Johnstone JM, Everson NW. The diagnostic value of symptoms and signs in childhood abdominal pain. JR Coll Surg Edinb. 1998;43(6):390-392.

14. Brewer BJ, Golden GT, Hitch DC, Rudolf LE, Wangensteen SL. Abdominal pain. An analysis of 1,000 consecutive cases in a University Hospital emergency room. Am J Surg. 1976;131(2):219-223.

15. Waseem M, Rosenberg HK. Intussusception. Pediatr Emerg Care. 2008;24(11):793-800.

16. Andersson RE, Hugander AP, Ghazi SH, et al. Why does the clinical diagnosis fail in suspected appendicitis? Eur J Surg. 2000;166(10):796-802.

17. Eskelinen M, Ikonen J, Lipponen P. Usefulness of history-taking, physical examination and diagnostic scoring in acute renal colic. Eur Urol. 1998;34(6):467-473.

18. Elton TJ, Roth CS, Berquist TH, Silverstein MD. A clinical prediction rule for the diagnosis of ureteral calculi in emergency departments. $J$ Gen Intern Med. 1993;8(2):57-62.

19. Leung AK, Robson WL. Urinary tract infection in infancy and childhood. Adv Pediatr. 1991;38:257-285.

20. Shaikh N, Morone NE, Lopez J, et al. Does this child have a urinary tract infection? JAMA. 2007;298(24):2895-2904.

21. Robson WL, Leung AK. Henoch-Schönlein purpura. Adv Pediatr. 1994;41:163-194.

22. Robson WL, Leung AK, Kaplan BS. Hemolytic-uremic syndrome. Curr Probl Pediatr. 1993;23(1):16-33.

23. Lim CJ, Chen JH, Chen WL, Shen YS, Huang CC. Jejunojejunum intussusception as a single initial manifestation of Henoch Schönlein purpura in a teenager. Am J Emerg Med. 2012;30(9):2085.e1-e3.
24. Moll van Charante E, de Jongh TO. Physical examination of patients with acute abdominal pain. Ned Tijdschr Geneeskd. 2011;155:A2658. Dutch.

25. Pogorelić Z, Mrklić I, Jurić I. Do not forget to include testicular torsion in differential diagnosis of lower acute abdominal pain in young males. J Pediatr Urol. 2013;9(6 Pt B):1161-1165.

26. Pogorelić Z, Mrklić I, Jurić I, Biočić M, Furlan D. Testicular torsion in the inguinal canal in children. J Pediatr Urol. 2013;9(6 Pt A):793-797.

27. Reust C, Williams A. Acute abdominal pain in children. Am Fam Physician. 2016;93(10):830-836.

28. Gans SL, Atema JJ, Stoker J, Toorenvliet BR, Laurell H, Boermeester MA. C-reactive protein and white blood cell count as triage test between urgent and nonurgent conditions in 2961 patients with acute abdominal pain. Medicine (Baltimore). 2015;94(9):e569.

29. Atema JJ, Gans SL, Beenen LF, et al. Accuracy of white blood cell count and C-reactive protein levels related to duration of symptoms in patients suspected of acute appendicitis. Acad Emerg Med. 2015;22(9):1015-1024.

30. Patrick GL, Stewart RJ, Isbister WH. Patients with acute abdominal pain: white cell and neutrophil counts as predictors of the surgical acute abdomen. N Z Med J. 1985;98(778):324-326.

31. Nauta RJ, Magnant C. Observation versus operation for abdominal pain in the right lower quadrant. Roles of the clinical examination and the leukocyte count. Am J Surg. 1986;151(6):746-748.

32. Kulik DM, Uleryk EM, Maguire JL. Does this child have appendicitis? A systematic review of clinical prediction rules for children with acute abdominal pain. J Clin Epidemiol. 2013;66(1):95-104.

33. Laurell H, Hansson LE, Gunnarsson U. Diagnostic pitfalls and accuracy of diagnosis in acute abdominal pain. Scand J Gastroenterol. 2006;41(10):1126-1131.

34. Toorenvliet BR, Bakker RF, Flu HC, Merkus JW, Hamming JF, Breslau PJ. Standard outpatient re-evaluation for patients not admitted to the hospital after emergency department evaluation for acute abdominal pain. World J Surg. 2010;34(3):480-486.

35. Abu-El-Haija M, Lin TK, Palermo J. Update to the management of pediatric acute pancreatitis: highlighting areas in need of research. $J$ Pediatr Gastroenterol Nutr. 2014;58(6):689-693.

36. Frank B, Gottlieb K. Amylase normal, lipase elevated: is it pancreatitis? A case series and review of the literature. Am J Gastroenterol. 1999;94(2):463-469.

37. Yang RW, Shao ZX, Chen YY, Yin Z, Wang WJ. Lipase and pancreatic amylase activities in diagnosis of acute pancreatitis in patients with hyperamylasemia. Hepatobiliary Pancreat Dis Int. 2005;4(4):600-603.

38. Couture E, Labbé V, Cyr C. Clinical predictors of positive urine cultures in young children at risk for urinary tract infection. Paediatr Child Health. 2003;8(3):145-149.

39. Wang PY, Chang HC, Lei RL, et al. Personal history and physical examination in judgment of urinary tract infection in children aged 3 months to 2 years. Pediatr Neonatol. 2016;57(4):274-279.

40. Webster DP, Schneider CN, Cheche S, Daar AA, Miller G. Differentiating acute appendicitis from pelvic inflammatory disease in women of childbearing age. Am J Emerg Med. 1993;11(6):569-572.

41. Guarino A, Ashkenazi S, Gendrel D, Lo Vecchio A, Shamir R, Szajewska H. European Society for Pediatric Gastroenterology, Hepatology, and Nutrition/European Society for Pediatric Infectious Diseases evidence-based guidelines for the management of acute gastroenteritis in children in Europe: update 2014. J Pediatr Gastroenterol Nutr. 2014;59(1):132-152.

42. Trowbridge RL, Rutkowski NK, Shojania KG. Does this patient have acute cholecystitis? JAMA. 2003;289(1):80-86.

43. Böhner H, Yang Q, Franke C, Verreet PR, Ohmann C. Simple data from history and physical examination help to exclude bowel obstruction and to avoid radiographic studies in patients with acute abdominal pain. Eur J Surg. 1998;164(10):777-784.

44. Rothrock SG, Green SM, Hummel CB. Plain abdominal radiography in the detection of major disease in children: a prospective analysis. Ann Emerg Med. 1992;21(12):1423-1429. 
45. Saito JM. Beyond appendicitis: evaluation and surgical treatment of pediatric acute abdominal pain. Curr Opin Pediatr. 2012;24(3):357-364.

46. Hayes R. Abdominal pain: general imaging strategies. Eur Radiol. 2004;14(Suppl 4):L123-L137.

47. Carty HM. Paediatric emergencies: non-traumatic abdominal emergencies. Eur Radiol. 2002;12(12):2835-2848.

48. Tabbers MM, DiLorenzo C, Berger MY, et al. Evaluation and treatment of functional constipation in infants and children: evidence-based recommendations from ESPGHAN and NASPGHAN. J Pediatr Gastroenterol Nutr. 2014;58(2):258-274.

49. Freedman SB, Thull-Freedman J, Manson D, et al. Pediatric abdominal radiograph use, constipation, and significant misdiagnoses. $J$ Pediatr. 2014;164(1):83-88.e2.

50. Shah S. An update on common gastrointestinal emergencies. Emerg Med Clin North Am. 2013;31(3):775-793.

51. Nosaka S, Hayakawa M, Miyazaki O, et al. Ultrasonography of pediatric right lower abdominal pain: correlation with clinical and pathological results. Nihon Igaku Hoshasen Gakkai Zasshi. 1995;55(12):855-860. Japanese.

52. Davies AH, Mastorakou I, Cobb R, Rogers C, Lindsell D, Mortensen NJ. Ultrasonography in the acute abdomen. Br J Surg. 1991;78(10): 1178-1180.

53. Mittal MK, Dayan PS, Macias CG, et al. Performance of ultrasound in the diagnosis of appendicitis in children in a multicenter cohort. Acad Emerg Med. 2013;20(7):697-702.
54. Bachur RG, Dayan PS, Bajaj L, et al. The effect of abdominal pain duration on the accuracy of diagnostic imaging for pediatric appendicitis. Ann Emerg Med. 2012;60(5):582-590.e3.

55. Lindelius A, Törngren S, Nilsson L, Pettersson H, Adami J. Randomized clinical trial of bedside ultrasound among patients with abdominal pain in the emergency department: impact on patient satisfaction and health care consumption. Scand J Trauma Resus Emerg Med. 2009;17:60.

56. Howell JM, Eddy OL, Lukens TW, Thiessen ME, Weingart SD, Decker WW; American College of Emergency Physicians. Clinical policy: critical issues in the evaluation and management of emergency department patients with suspected appendicitis. Ann Emerg Med. 2010;55(1):71-116.

57. Marincek B. Nontraumatic abdominal emergencies: acute abdominal pain: diagnostic strategies. Eur Radiol. 2002;12(9):2136-2150.

58. Hwang BH, Kim Y, Chae GB, Moon SB. Predictors of positive CT yield in pediatric patients with nontraumatic abdominal pain. Pediatr Emerg Care. Epub 2016 Oct 6.

59. Poonai N, Paskar D, Konrad SL, et al. Opioid analgesia for acute abdominal pain in children: a systematic review and meta-analysis Academic Emerg Med. 2014;21(11):1183-1192.

60. Manterola C, Vial M, Moraga J, Astudillo P. Analgesia in patients with acute abdominal pain. Cochrane Database Syst Rev. 2011;(1):CD005660.

61. Schurman JV, Hunter HL, Friesen CA. Conceptualization and treatment of chronic abdominal pain in pediatric gastroenterology practice. $J$ Pediatr Gastroenterol Nutr. 2010;50(1):32-37.
Pediatric Health, Medicine and Therapeutics

\section{Publish your work in this journal}

Pediatric Health, Medicine and Therapeutics is an international, peerreviewed, open access journal publishing original research, reports, editorials, reviews and commentaries. All aspects of health maintenance, preventative measures and disease treatment interventions are addressed within the journal. Practitioners from all disciplines are invited to submit

\section{Dovepress}

their work as well as healthcare researchers and patient support groups. The manuscript management system is completely online and includes a very quick and fair peer-review system. Visit http://www.dovepress.com/ testimonials.php to read real quotes from published authors. 